\title{
Ocorrência de Ungla Navás (Neuroptera, Chrysopidae) no Brasil e descrição de nova espécie
}

\author{
Sérgio de Freitas ${ }^{1}$ \\ ${ }^{1}$ Departamento de Fitossanidade, Universidade Estadual Paulista. Via de Acesso Prof. Paulo Donato Castellane s/n, 14884-900 Jaboticabal-SP, \\ Brasil.serfre@fcav.unesp.br.
}

\begin{abstract}
Occurrence of Ungla Navas (Neuroptera, Chrysopidae) in Brazil and description of a new species. The Neotropical genus Ungla Navás, 1914 is recorded for the first time in the Brazilian ecosystem. A new species is described from Sete Lagoas, Minas Gerais, Brazil. A key for the Ungla species is added.
\end{abstract}

KEYWORDS. Biological control; green lacewings; predator.

RESUMO. Ocorrência de Ungla Navás (Neuroptera, Chrysopidae) no Brasil e descrição de nova espécie. Pela primeira vez é registrada a ocorrência do gênero Neotropical Ungla Navás, 1914 em ecossistema brasileiro. Uma nova espécie é descrita para Sete Lagoas, Minas gerais, Brasil. Uma chave para espécies de Ungla é fornecida.

PALAVRAS-CHAVE. Bicho lixeiro; controle biológico; predador.

Dentre os Chrysopidae, a subfamília Chrysopinae é a que possui maior número de espécies, sendo a tribo Chrysopini a mais bem representada na entomofauna brasileira. Nesta tribo estão alocados os gêneros: Chrysoperla Steinmann, 1964, Ceraeochrysa Adams, 1982, Chrysopodes (Chrysopodes) Navás, 1913, Chrysopodes (Neosuarius) Adams \& Penny, 1987, Plesiochrysa Adams, 1982, Leucochrysa (Leucochrysa) McLachlan, 1868, Leucochrysa (Nodita) Navás, 1916 (Freitas \& Penny, 2001). Cryptochrysa Freitas \& Penny, 2000, Furcochrysa Freitas \& Penny, 2000 (Freitas \& Penny, 2000). Um amplo relato das espécies de crisopídeos encontrados no Brasil foi realizado por Freitas \& Penny (2001), entretanto, nenhuma espécie do gênero Ungla foi registrada.

O gênero Ungla foi descrito por Navás, 1914, com base em Ungla annulata Navás, 1914, a única espécie incluída na ocasião. Adams (1975) reviu o gênero e concluiu que as suas características eram compartilhadas com as de Suarius Navás, 1914, sendo, portanto considerado por ele como sinônimo. Segundo Adams (1975) o caráter diferencial deste grupo está nas pernas anteriores bastante desenvolvida e semelhante à pernas de mirmeleontídeos (Neuroptera, Myrmeleontidae). Entretanto esta característica não pode ser considerada única, pois ela não é tão desenvolvida a ponto de ser nitidamente distinguida como afirma Adams (1975).

Brooks \& Barnard (1990) concluíram, contrariando Adams (1975), que o gênero Ungla é válido e, vincularam a ele espécies de ocorrência neotropical registradas para Argentina e Peru. São elas: U. argentina (Navás, 1911) (=U. annulata Navás, 1914), U. binaria (Navás, 1923), U. confraterna (Banks, 1913) e U. nesotala (Banks, 1944).

Monserrat \& Freitas (2005) estudaram espécies de crisopídeos da Patagônia e Terra do Fogo e acrescentaram novas características morfológicas às descrições $U$. argentina e U. binaria. Verificaram ainda, uma variação distinta da genitália masculina.

Segundo Brooks \& Barnard (1990) as espécies de Ungla podem ser reconhecidas pelas seguintes características: adulto de coloração basicamente verde, asa anterior de comprimento entre $11-13 \mathrm{~mm}$, cabeça marcada com manchas marrons no vértice, gena e entre as antenas; palpo achatado apicalmente, labro emarginado, mandíbulas largas, vértice elevado sem estrias, escapo tão largo quanto longo; pronoto marcado com manchas marrons, cerdas curtas e pretas; meso e metanoto sem marcas, pernas sem marcas com cerdas pretas curtas, garras sem dilatação na base; asas posteriores estreitas e sem marcas. Abdome sem marcas, ectoprocto fortemente invaginado; genitália do macho sem tignum, gonapsis, placa mediana, pseudopênis, entoprocessus e parâmeros; gonarcus com longo e sinuoso processo lateralmente; arcessus estreito, gonossacus com longas gonosetas; genitália da fêmea com espermateca curta e estreita, ducto longo e sinuoso.

\section{MATERIALE MÉTODOS}

Uma oviposição foi coletada pela equipe do Dr. Ivan Cruz em plantios de milho, no município de Sete Lagoas, Minas Gerais, no Centro Nacional de Pesquisa em Milho e Sorgo, da Empresa Brasileira de Pesquisa Agropecuária (EMBRAPA CNPMS). Os ovos foram levados ao laboratório e as larvas eclodidas criadas para obtenção dos adultos. As larvas, alimentadas com ovos de Anagasta kuehniella (Zeller) (Lepidoptera, Pyralidae), foram criadas em ambiente com temperatura de $25 \pm 1^{\circ} \mathrm{C}, 70 \pm 10 \%$ UR, e 12 horas de fotofase.

Extremidades dos abdomens foram maceradas em solução de hidróxido de potássio a $10 \%$ por uma hora e corada em "clorazol black". A genitália foi exteriorizada para as observações e confecção dos desenhos. 
As larvas foram sacrificadas em água quente, colocadas em solução de hidróxido de potássio por uma hora e clarificadas com ácido acético.

\section{Ungla Navás, 1914}

Ungla Navás, 1914: 224 (Espécie-tipo: Ungla annulata Navás, 1914, por designação original e monotipia).

Suarius Navás, 1914; Adams, 1975: 169 (syn.).

\section{Ungla ivancruzi sp.nov.}

(Figs. 1-18)

Material-tipo. Holótipo macho. BRASIL. Minas Gerais, Sete Lagoas, EMBRAPA, CNPMS, Lab., 16.I.2007 (S. de Freitas), (MZSP Museu de Zoologia, Universidade de São Paulo). Parátipos: 7 machos e 6 fêmeas, mesmos dados do holótipo (Departamento de Fitossanidade, UNESP - Jaboticabal, São Paulo).

Etimologia. Esta espécie é dedicada ao pesquisador, entusiasta entomologista, Dr. Ivan Cruz, do Centro Nacional de Pesquisa em Milho e Sorgo, Empresa Brasileira de Pesquisa Agropecuária (EMBRAPA), que vem se dedicando a otimização do Controle Biológico de pragas agrícolas no Brasil.

Diagnose. Insetos pequenos $(1,0-1,5 \mathrm{~cm})$ de coloração amarelo-esverdeado, com manchas escuras em meia lua lateralmente na parte elevada do vértice. Além das diferenças na genitália, esta espécie pode ser distinguida das outras por apresentar manchas marrom-claras na cabeça, pro, meso e metanoto; palpo maxilar sem pigmentação. Genitália do macho com gonarcus fortemente arqueado, sendo seu braço estreito e sem projeção frontal, arcessus largo.

Macho. Cabeça. Vértice amarelo, elevado, liso e brilhante com mancha circular vermelho escura/marrom (Figs. 1,3). Fronte amarela sem manchas (Fig. 2); gena marrom claro (Fig. 4); palpo maxilar claro, último palpômero 1,5 vezes mais longo que o anterior (Fig.4); escapo amarelo-claro com mancha vermelha dorsomediana que se prolonga sobre o vértice, pedicelo e flagelo amarelo-claro; flagelômeros com filas de cerdas pretas.

Tórax. Verde amarelado; pronoto com manchas laterais marrons bem definidas (Figs. 1,3); dorsalmente com várias cerdas pretas (Fig. 3); meso e metanoto com manchas laterais marrons difusas (Fig. 1). Asa anterior: veias longitudinais verdes e as transversais pretas (Fig.5); comprimento 9,5 (7,9$10,2) \mathrm{mm}$ (Fig. 5). Asa posterior: venação predominante verde; costais tranversais, transversais radiais e gradiformes pretas; comprimento 8,4 (7,2-9,2) mm (Fig. 5).

Abdome. Verde amarelado sem manchas. Macho: gonarcus fino e arqueado sem formação de ângulos (Fig. 6); braços do gonarcus estreito com projeção mediana (Fig. 7); arcessus largo com inúmeras microcerdas e com processo curvo em forma de chifre na extremidade posterior (Fig. 8); gonossacus com tufos laterais de cerdas longas (Figs. 6, 8).

Fêmea. Similar ao macho. Espermateca curta (Fig. 9); subgenitalia com processo caudal curvado dorsalmente (Fig. 10).

Estágios imaturos. Os ovos são colocados em grupos de 10 a 16 e mantidos sobre um único pedicelo (Fig.11). Larva de primeiro ínstar (Figs. 12, 13). Cabeça com mancha central em forma de "Y"; manchas laterais prolongando-se por toda a superfície cefálica; corpo coberto com filas transversais de longas cerdas lisas ou com ganchos na extremidade; tubérculos laterais digitiformes no pro e mesonoto com 3-4 cerdas longas; abdome com pequenos tubérculos laterais com cerdas longas. Larva de segundo ínstar (Figs. 14, 15). Corpo giboso e arqueado. Cabeça com manchas do mesmo padrão que larvas de primeiro ínstar; pro e mesonoto sem cerdas dorsais; metanoto com uma fila transversal de cerdas longas e retas; pro, meso e mesotórax com projeções digitiformes laterais com longas cerdas; dorso do abdome com filas de cerdas curtas e extremidades curvas, tubérculos laterais com tufos de cerdas longas e curtas de extremidade reta. Larva de terceiro ínstar (Figs. 16, 17, 18). Corpo sub-cilíndrico, coloração branca e coberto dorsalmente por microtríquias; parte anterior do abdome mais volumoso e arqueado; dorso com alta densidade de cerdas muito comum em transportadores de resíduos (lixo); cerdas de três tipos: reta e lisa, lisa e em gancho e espinhosa. Cabeça: cor âmbar, com manchas dorsais escuras: dois pares laterais e um par central (Fig.18); quetotaxia cefálica com cerdas primárias (C1-C12) presentes, cerdas 1 e 11 muito longas; antenas claras com uma grande cerda apical. Tórax. Achatado com tubérculos laterais digitiformes sendo o primeiro par mais longo que o segundo e este maior que o terceiro; protórax com tubérculos com cerdas apicais serreadas e espinhosas dirigidas frontalmente, dois escleritos escuros laterais; mesotórax com projeções laterais curtas e cerdas serreadas e espinhosas dirigidas lateralmente; metatórax com pequenas projeções laterais com cerdas apicais mais curtas serreadas e espinhosas, uma fila de 10 cerdas longas; pernas claras sem manchas, garras curvas e empódio escuro. Abdome mais volumoso que o tórax, dorso coberto de filas de cerdas curvas e em gancho, tubérculos laterais pequenos com cerdas curtas, tubérculos dorsais (últimos segmentos) com longas cerdas.

Comentários. Esta espécie é muito próxima às demais do gênero Ungla, havendo diferenças na presença, forma e cor das manchas na cabeça e tórax, bem como diferenças na genitália do macho.

Chave para as espécies de Ungla

1. Manchas vermelho-marron claro na cabeça, pronoto e mesonoto; gonarcus fortemente arqueado; braço do gonarcus sem projeção frontal, arcessus largo ........ Ungla ivancruzi

Manchas pretas na cabeça, pronoto e mesonoto; gonarcus levemente arqueado; braço do gonarcus com projeção frontal; arcessus estreito

2

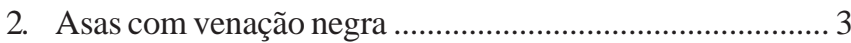

Asas com venação predominante verde .............................. 4 

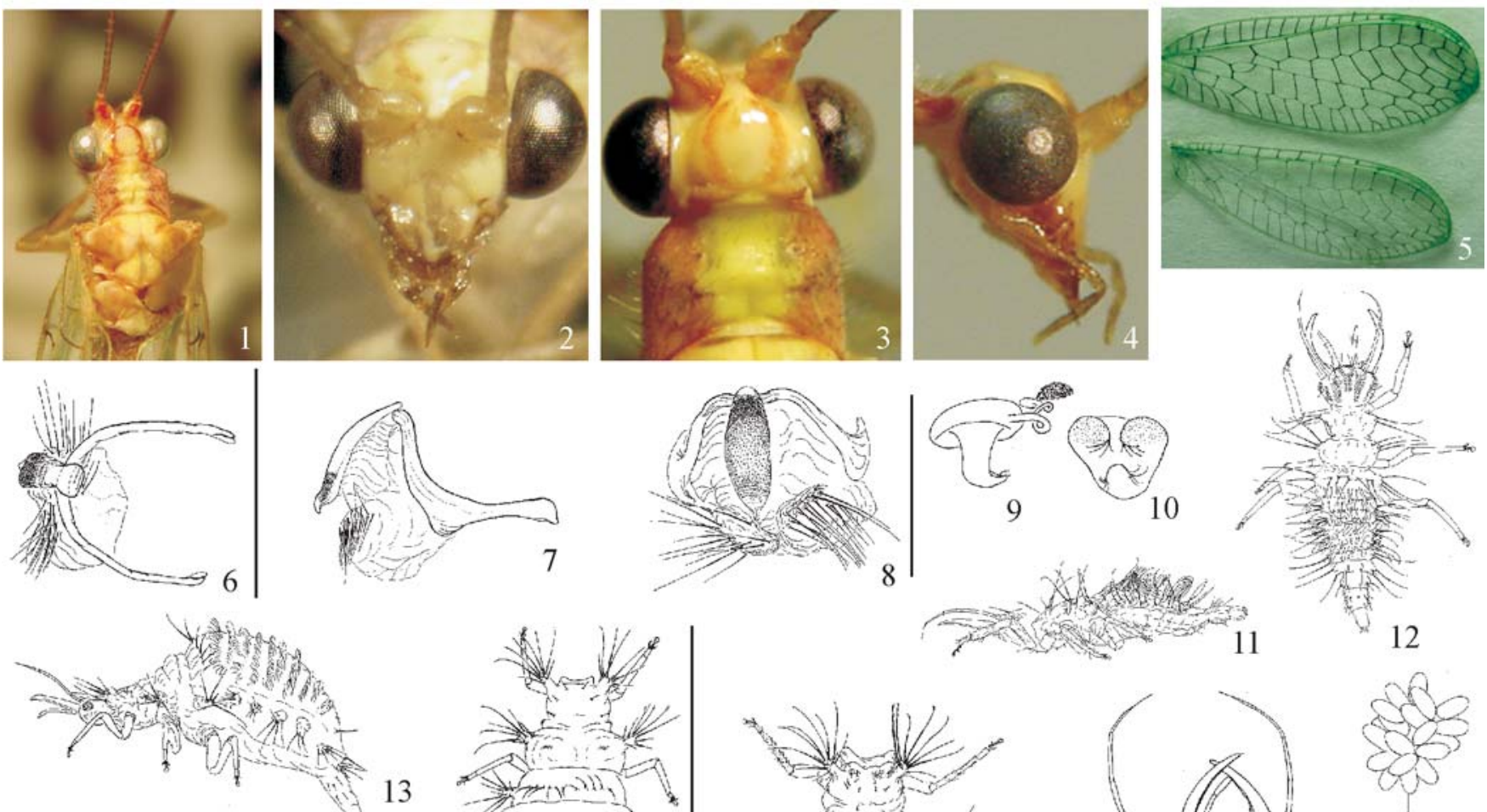

13
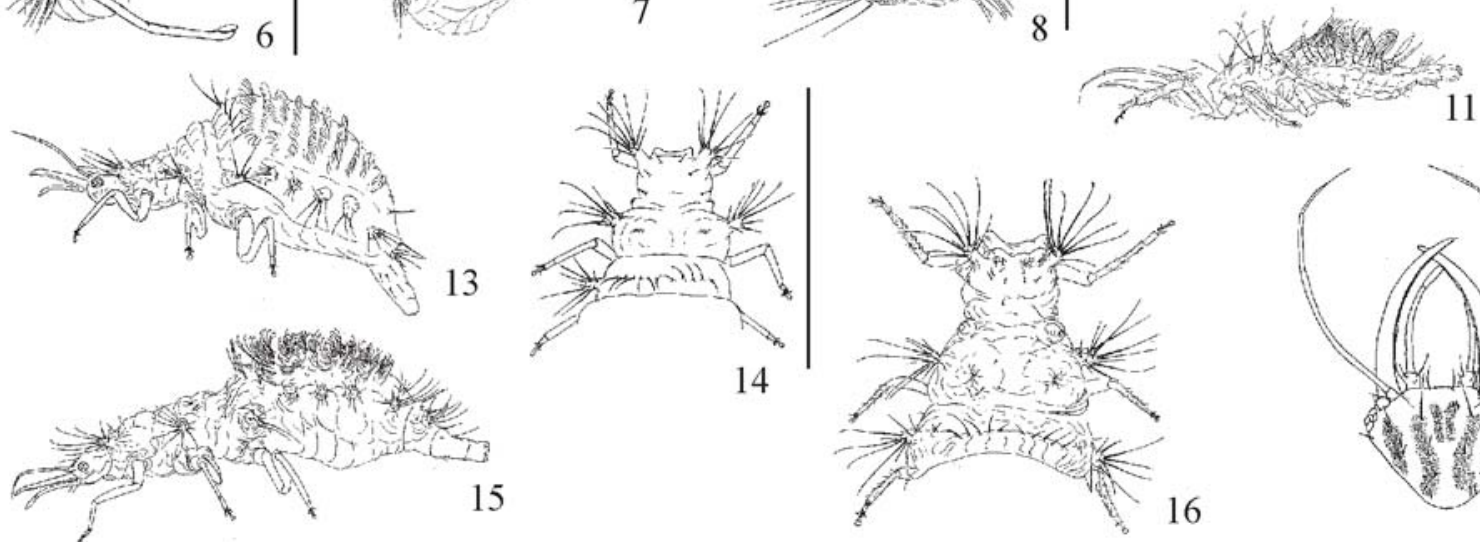

12
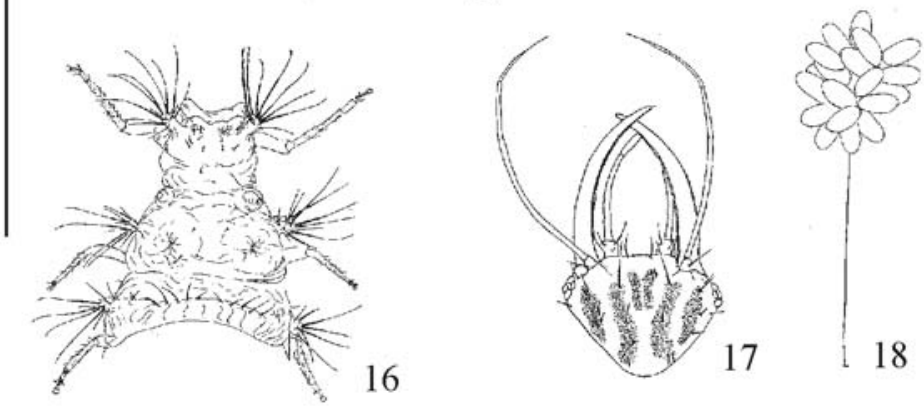

Figs. 1-18. Ungla ivancruzii sp. nov.: 1, vista dorsal; 2, cabeça, vista frontal; 3, cabeça e protórax, vista dorsal; 4, cabeça, vista lateral; 5, asas; genitália masculina; 6, vista dorsal; 7, vista lateral; 8, vista frontal; 9, espermateca; 10, subgenitalia; 11. postura; larva de primeiro instar; 12, vista lateral; 13, vista dorsal; larva de segundo instar; 14, vista lateral; 15, tórax, vista dorsal; larva de terceiro instar; 16, vista lateral; 17, tórax, vista dorsal; 18, cabeça.

3. Pronoto com densa cobertura de cerdas pretas; gonarcus estreito e com longa projeção frontal do braço do gonarcus U. binaria

Gonarcus largo, curta projeção frontal do braço do gonarcus expandido U. argentina

4. Braço do gonarcus com projeção frontal ....... U. nesotala Braço do gonarcus sem projeção frontal .... U. confraterna

Agradecimentos. Agradecemos ao Dr. Ivan Cruz, pesquisador do Centro Nacional de Pesquisa de Milho e Sorgo, EMBRAPA, por fornecer o material de estudo e ao Dr. Norman Dale Penny que prontamente nos atendeu e nos enviou a descrição original, os desenhos e observações sobre os holótipos de Ungla confraterna e U. nesotala realizados pelo Dr. Phillip A. Adams, constantes dos "Cadernos de anotações" deste já falecido neuropterólogo.

\section{REFERÊNCIAS}

Adams, P. A. 1975. Status of the genera Ungla and Mallada Navás (Neuroptera: Chrysopidae). Psyche 82: 167-173.

Adams, P. A. \& N. D. Penny. 1987. Neuroptera of the Amazon Basin. Part 11a. Introduction and Chrysopini. Acta Amazonica 15: 413479.

Brooks, S. J. \& P. C. Barnard. 1990. The green lacewings of the world: a generic review (Neuroptera: Chrysopidae). Bulletin of the British Museum Natural History (Entomology) 59: 117286.

Freitas, S. de \& N. D. Penny. 2000. Two new genera of Neotropical Chrysopini (Neuroptera: Chrysopidae). Journal of the Kansas Entomological Society 73: 164-170.

Freitas, S. de \& N. D. Penny. 2001. The green lacewings (Neuroptera: Chrysopidae) of Brazilian Agro-ecosystems. Proceedings of the California Academy of Sciences 52: 245-395.

Monserrat, V. J. \& S. de Freitas. 2005. Contribución al conocimiento de los crisópidos de Coquimbo, Patagônia y Tierra Del Fuego (Argentina, Chile) (Insecta, Neuroptera, Chrysopidae). Graellsia 16: $163-179$.

Navás, L. 1914. Neurópteros sudamericanos. Broteria 12: 45-56, 215-234. 